\title{
RESEARCH OF THE MARKET OF LAND PROPERTY RIGHTS IN THE ASPECT OF THE INSTITUTIONAL THEORY ${ }^{1}$
}

\author{
Elena N. Fedyunina \\ Volgograd State Agrarian University, Volgograd, Russian Federation \\ Liliya O. Oganesyan \\ Volgograd State Agrarian University, Volgograd, Russian Federation
}

\begin{abstract}
The article reveals the essence, the structure of the market of land property rights presented as a single system of socio-economic sanctioned rules of behavior of economic entities and contractual relations on transaction, specification and implementation of alternative methods of full or limited land property rights in short and long time periods. In the process of the research the authors reveal the features of functioning of the market of full and limited land property rights, specify the subject and object of the research, the character of exchange, the mechanism of implementing market and institutional transaction. Based on conceptual approaches of leading experts, both Western and Russian-built ones, the authors propose an algorithm of the market analysis, justify the dual market model of full and limited property rights on agricultural land, present more models of supply and demand of full rights of land ownership and market of management rights, prove leadership and institutional factors in the structure of non-price determinants of supply and demand. On the one hand, institutional factors influence the creation of a limited framework of behavior of market participants in the process of interaction, and on the other hand, set the structure of incentives for land owners in short and long term. The theoretical model was tested in the course of the empirical research in the framework of the scientific project "Monitoring the Functioning of Local Agricultural Land Markets", the hypothesis of domination of institutional non-price determinants in the market model was confirmed and the need for market institutionalization was justified.

Key words: methodology, research methods, market of land property rights, market model, structural market dichotomy, institute.

Citation. Fedyunina E.N., Oganesyan L.O. Research of the Market of Land Property Rights in the Aspect of the Institutional Theory. Journal of Volgograd State University. Economics, 2019, vol. 21, no. 4, pp. 44-54. (in Russian). DOI: https://doi.org/10.15688/ek.jvolsu.2019.4.5
\end{abstract}

\section{ИССЛЕДОВАНИЕ РЫНКА ПРАВ ЗЕМЕЛЬНОЙ СОБСТВЕННОСТИ В АСПЕКТЕ ИНСТИТУЦИОНАЛЬНОЙ ТЕОРИИ ${ }^{1}$}

\author{
Елена Николаевна Федюнина \\ Волгоградский государственный аграрный университет, г. Волгоград, Российская Федерация \\ Лилия Оганесовна Оганесян \\ Волгоградский государственный аграрный университет, г. Волгоград, Российская Федерация
}

Аннотация. В статье раскрыта сущность, структура рынка прав земельной собственности, представ-
ленная как единая система социально-экономических санкционируемых правил поведения экономических
субъектов и контрактных отношений по поводу трансакции, спецификации и реализации альтернативных
способов полных или ограниченных прав земельной собственности в краткосрочном и долгосрочном вре- 
менных периодах. В процессе исследования выявлены особенности функционирования рынка полных и ограниченных прав земельной собственности, конкретизированы предмет и объект исследования, характер обмена, механизм реализации рыночной и институциональной трансакции. Базируясь на концептуальные подходы ведущих специалистов (как западных, так и отечественных), выстроен алгоритм анализа рынка, обоснована дуальная модель рынка полных и ограниченных прав собственности на сельскохозяйственные земли, представлены авторские модели спроса и предложения полных прав земельной собственности и рынка прав хозяйствования, доказаны преимущественные позиции институциональных факторов в структуре неценовых детерминантов спроса и предложения. С одной стороны, институциональные факторы влияют на создание ограниченных рамок поведения участников рынка в процессе взаимодействия, а с другой задают структуру побудительных мотивов собственников земли в краткосрочном и долгосрочном периодах. Теоретическая модель апробирована в ходе эмпирических исследований в рамках научного проекта «Мониторинг функционирования локальных рынков сельскохозяйственных земель», подтверждена гипотеза доминирования институциональных неценовых детерминантов в модели рынка и обоснована необходимость институционализации рынка.

Ключевые слова: методология, методы исследования, рынок прав земельной собственности, модель рынка, структурная дихотомия рынка, институт.

Цитирование. Федюнина Е. Н., Оганесян Л. О. Исследование рынка прав земельной собственности в аспекте институциональной теории // Вестник Волгоградского государственного университета. Экономика. - 2019. - Т. 21, № 4. - C. 44-54. - DOI: https://doi.org/10.15688/ek.jvolsu.2019.4.5

\section{Введение}

В современной экономической науке многие ученые стали активно исследовать различные направления институциональной теории, однако в настоящее время не сложилось системного взгляда относительно понимания сущности рынков факторов производства как института и исследование в этом контексте рынка права земельной собственности (сельскохозяйственные земли). Традиционно в экономической теории рынок земли рассматривается как рынок фактора производства или рынок природных (естественных) земельных ресурсов и несельскохозяйственных земель. Спрос на землю включает два основных вида: на сельскохозяйственные и несельскохозяйственные земли.

Как правило, в классических и неоклассических концепциях ресурсного рынка, учебной литературе, в частности, в учебниках по микроэкономике, выдвигаются положения о производном спросе на рынке земли от спроса на продовольственном рынке, неэластичности спроса и абсолютной ограниченности предложения. Однако практически все исследователи ограничивают свой анализ законом спроса и предложения и принципом формирования дифференциальной земельной ренты, что затрудняет объективное отражение всего сложного процесса функционирования ресурсного рынка и в частности механизма вза- имодействия участников рынка по поводу эффективного использования редких ресурсов. В результате этого за пределами анализа остаются институциональные сделки на рынках, в рамках которых отчуждается право пользования земельной собственностью - право хозяйствования - посредством контрактов, имеющих определенный временной период. Для решения данной проблемы в качестве объекта обмена следует рассматривать не земельный участок, как это практикуется во многих исследованиях, а право на земельный ресурс. Такой подход позволяет определить характер обмена в арендных отношениях, в рамках которых передается лишь право хозяйствования на сельскохозяйственные земли. В отличие от товарного рынка в обмене принимают участие не только продавцы и покупатели, но и третьи лица - органы местной, региональной и федеральной власти. Они выступают в качестве организатора торгов по продаже и аренде сельскохозяйственных земель и гарантов данных сделок. Таким образом, на практике формируется система институциональных отношений по поводу трансакции и спецификации полных и ограниченных прав собственности между участниками рынка, в качестве которых выступают собственники земли: физические и юридические лица, органы власти различного уровня.

На наш взгляд, при анализе механизма функционирования рынка земли необходимо, 
прежде всего, учитывать дуальный характер рынка, отражающий рыночные и институциональные отношения, обусловленные характером обмена на факториальном (ресурсном) рынке [Оганесян и др., 2014, с. 105-106; Оганесян и др., 2015, с. 30; Оганесян и др., 2019, c. 158; Федюнина и др., 2018]. После этого необходимо конкретизировать характер обмена, механизм реализации рыночной и институциональной сделки с учетом особенностей функционирования рынка земли. По своей природе рынки факторов производства отличаются от товарного рынка тем, что они являются рынками «фиктивных товаров» [Polany, 1944] и относятся к категории «социально значимый рынок» [Оганесян и др., 2014, с. 102-103]. Обмен на рынке земли осуществляется в условиях институциональных ограничений, обусловленных действующим режимом права земельной собственности и социальной значимостью земли. Эти обстоятельства позволяют нам рассматривать рынок права на земельную собственность, выдвинуть гипотезу о структурной дихотомии рынка, доминировании институциональных факторов в моделях спроса и предложения полных и ограниченных прав.

\section{Методология исследования}

Методологической основой анализа рынка прав земельной собственности послужили те концепции, которые способствовали формированию следующих подходов к исследованию рынка:

- концепция факториальных рынков «фиктивных товаров» К. Поланьи [Polany, 1944; Поланьи, 2002] позволила обосновать дуальную структуру механизма функционирования рынков факторов производства, выделив рыночные и институциональные механизмы, и определить роль рынка прав земельной собственности в социально-экономической системе;

- концепция социально значимых рынков труда и образовательных услуг Е.Г. Гущиной [Гущина и др. 2010, с. 43-46; Gushchina, 2012, c. 34-35] послужила основой определения критериев социальной значимости рынка прав земельной собственности;

- экономическая теория права собственности А.А. Алчиана [Алчиан, 2004; Alchian et al., 1973], С. Пейовича [Peiovich, 1994], Э. Фуруботна [Furubotn et al., 1972], А. Оноре [Honore, 1961], Р.И. Капелюшникова [Капелюшников, 1990], экономическая теория права земельной собственности Н.И. Кресниковой [Кресникова, 2003], А.Н. Макарова [Макаров, 2007], Ю.Ф. Аношиной [Аношина, 2011], Е.Н. Федюниной, Л.О. Оганесян [Федюнина и др., 2018, с. 400] способствовала определению сущности права собственности на сельскохозяйственные земли, представленной нами как социально-экономические и санкционированные поведенческие отношения, возникающие между людьми по поводу рыночной трансакции прав собственности, способов отчуждения права на земельную собственность и использования редких ресурсов;

- концепция рынка института С. Пейовича [Pejovich,1996, с. 117-118], Д. Норта [Норт, 1997], В.Л. Тамбовцева [Тамбовцев, 2001] стала основой определения авторами понятия рынка института земельной собственности как единой системы санкционируемых правил поведения экономических агентов и механизма социальной защиты, в рамках которой предоставляется право на альтернативный выбор способов использования редкого блага, гарантии защиты прав собственности на сельскохозяйственные земли со стороны государства и определяются условия конкуренции, рыночной трансакции, спецификации полного или ограниченного права земельной собственности;

- концепция шестифакторной модели производственной функции и «ядра развития» экономической системы О.В. Иншакова [Иншаков, 2003, с. 18-19] - принципы классификации факторов в новой производственной функции (трансформационные, трансакционные) легли в основу формирования моделей спроса и предложения на рынке прав собственности на сельскохозяйственные земли [Оганесян, 2019, с. 158-159].

\section{Результаты и обсуждение}

По классическим законам саморегулирующего рынка, последний должен быть свободен и обособлен в институциональном плане. Однако институциональная обособленность рынка земли как фактора производства недо- 
пустима, так как земельный ресурс (сельскохозяйственные земли) обладает свойством общественной полезности, а право земельной собственности определяется как редкий ресурс. Согласно утверждению К. Поланьи, с одной стороны, рынки факторов производства (труда, земли, капитала) являются рынками фиктивных товаров, так как эти товары не производятся для продажи. С другой стороны, факторы производства в силу своей общественной значимости включены в более широкую социально-экономическую систему. По этой причине недопустимо отнесение таких факторов производства, как труд и земля в качестве составных элементов только в рыночный механизм, так как в противном случае это означает «признание подчинения субстанции самого общества законам рынка» [Polany, 1944, с. 68-70]. В этом контексте рынок сельскохозяйственных земель можно рассматривать как рынок социально-значимого блага, обладающего амбивалентным (двойственным) характером, общественной и индивидуальной значимостью и полезностью [Gushchina, 2012; Оганесян и др., 2015]. На наш взгляд, общественная или социальная значимость рынка земли обусловлена социальной полезностью, масштабами создаваемых положительных эффектов, величиной постоянного совокупного спроса на производном рынке продовольствия и ролью рынка в обеспечении продовольственной безопасности национальной экономики [Оганесян и др., 2014, с. 102].

В силу специфики рынков факторов производства поведение экономических агентов формирует не экономика, а социальные организации и институты [Поланьи, 2002, с. 1]. Следовательно, с одной стороны, рынок прав земельной собственности функционирует по закону спроса и предложения, а с другой - в рамках формальных и неформальных правил, в условиях институциональных ограничений. Исходя из этого, механизм функционирования рынка прав собственности на сельскохозяйственные земли представляет собой совокупность экономических элементов рыночного саморегулирования и институциональных регуляторов.

На наш взгляд, механизм функционирования рынка прав земельной собственности является дуальным с доминированием эле- ментов институционального механизма [Оганесян и др., 2015, с. 30] и гибридным. Основным показателем эффективного функционирования институционального механизма выступает величина трансакционных издержек. Институциональный механизм рынка прав земельной собственности приоритетнее экономического. Это объясняется тем, что институты задают поведение индивидов и регулируют взаимоотношения агентов рынка в процессе обмена [Норт, 1997]. По своей сути, как отмечают А.Ю. Веретенникова, Ж.К. Омонов, институциональный механизм обеспечивает последовательность действий экономических агентов, направленных на эффективное взаимодействие участников рынка посредством выполнения формальных и неформальных норм с целью достижения экономического результата [Веретенникова и др., 2017, с. 160-161].

Противопоставляя принципы институционального анализа неоклассическому, С. Пейович отметил, что результаты хозяйственной деятельности в большей мере зависят от преобладающих прав собственности и договорного права, чем от уровня технологии в неоклассической производственной функции [Pejovich, 1994]. С точки зрения выполняемой социальной функции права собственности предстают как определенные «правила игры», регулирующие взаимоотношения между людьми по поводу редких ресурсов, а с точки зрения их внутреннего содержания как «пучки правомочий», которыми располагают отдельные агенты [Капелюшников, 1990]. Следует отметить, что сила права собственности определяется набором правомочий и измеряется издержками реализации (enforcement) права, которые зависят как от формальных правил, так и от «неформальных общественных акций и господствующих этических и моральных норм» [Алчиан, 2004, с. 714]. В условиях рыночной конкуренции и институциональных ограничений приходится решать проблему выбора правил игры и «пучка правомочий», определять принципы поведения на рынке и добровольных взаимодействий индивидов. В этом контексте важнейшей функцией конкурентного рынка становится «поощрение институциональных инноваций и форм адаптивного поведения участников рынка» [Pejovich, 1996, с. 117], а так- 
же эффективное распределение редких ресурсов. В институциональной теории право собственности - это обеспечиваемое обществом право на выбор альтернативных способов использования экономического блага [Алчиан, 2004, с. 714-715], и в этом плане человек становится собственником прав, обеспечивающих ему социально признанные действия. На основе выбора «пучка правомочий» агенты рынка практически выбирают формы пользования земельными ресурсами и способы организации хозяйственной деятельности. В составе института права собственности выделяются основные формальные правила поведения экономических агентов и гарантов выполнения правил [Тамбовцев, 2001, с. 25].

На рынке прав земельной собственности совершаются институциональные сделки - совместные действия агентов рынка, направленные на отчуждение или перераспределение правомочий собственности, в которых участвует третья сторона - формальные институты, выступающие в качестве гаранта защиты прав собственников. По определению В.Л. Тамбовцева, институциональные сделки делятся на явные и неявные. Если явные институциональные сделки определяются как совместные действия индивидов, направленные на изменение существующего институционального устройства, то неявные сделки обусловлены выбором того или иного правила, в соответствии с которым осуществляются действия в связи с желанием совершить некоторую товарную сделку на локальном рынке [Тамбовцев, 2001, с. 27]. На рынке прав земельной собственности заключаются неявные сделки, так как отчуждаются в зависимости от выбора полные или ограниченные права собственности, соответственно формируются два рынка: рынок полных прав земельной собственности и рынок прав хозяйствования (рынок аренды сельскохозяйственных земель).

Модель экономического поведения индивидуума на рынках меняется под влиянием институциональных изменений - экзогенных и эндогенных [Peiovich, 1994]. Если экзогенные институциональные изменения на рынке прав земельной собственности обусловлены новыми законами и нормами земельного за- конодательства, программой развития или реформирования аграрной экономики, то эндогенные институциональные изменения - необходимостью определения способов адаптации к изменениям институциональной среды и формирования стабильного набора правил. Эндогенные институциональные изменения возникают на базе взаимодействия интересов и добровольного неформального согласия участников рынка. В процессе институциональных изменений, как показывают проведенные исследования, возникает ситуация, когда формальные и неформальные правила дополняют друг друга или вовсе несовместимы. Несовместимость формальных и неформальных правил поведения на протяжении проведения земельной реформы в России были вызваны особенностями механизма распоряжения земельной долей. Согласно земельному законодательству обмен полными правами на землю состоится в том случае, если земельная доля трансформируется в земельный участок, что сопряжено с высокими трансакционными издержками. Специфика механизма реализации земельной доли обусловливает необходимость определения вектора направления институциональных изменений в современной аграрной экономике России.

В целом на рынке прав земельной собственности, как правило, формируется система экономических и институциональных отношений по поводу альтернативных способов реализации полных или ограниченных прав земельной собственности в краткосрочном и долгосрочном периодах времени. Если в краткосрочном периоде в основном осуществляется трансакция полных прав, то в среднесрочном и долгосрочном периодах проводится трансакция ограниченных прав различных форм собственности - индивидуальной, коллективной, долевой, государственной.

Эффективность функционирования рынка прав земельной собственности обусловлена действием институциональных и экономических факторов. Институциональные факторы при этом создают долгосрочные возможности реализации функций экономической системы. Институты обусловливают принципы формирования базовой модели «пучка правомочий» и структуры рынка, выбор правил игры и проявление трансакционных издержек. 
В процессе функционирования рынка важную значимость приобретает показатель соотношения трансформационных и трансакционных издержек [Попов и др., 2016, с. 118, 121-123]. Проведенное исследование природы и специфики рынка прав земельной собственности в контексте основных принципов институциональной теории позволяет построить модель рынка полных и ограниченных прав собственности на сельскохозяйственные земли и обосновать доминирующую роль институциональных факторов в структуре неценовых детерминантов спроса и предложения. При построении моделей спроса и предложения полных и ограниченных прав на сельскохозяйственные земли согласно общепринятому подходу учитываем ценовые факторы и такие неценовые детерминанты, как численность собственников-продавцов, текущие и будущие доходы, издержки, факторы ожидания и неожиданности. Однако на рынке прав земельной собственности структурные изменения в спросе и предложении происходят в большей мере под влиянием институциональных факторов: институциональные регуляторы (нормы и правила, налоговые ставки), трансакционные издержки функционирования рынка, риски оппортунизма и контрактации, что подтверждают результаты эмпирических исследований.

Для анализа действия и значимости неценовых детерминантов спроса и предложения на рынках полных и ограниченных прав земельной собственности был проведен мониторинг функционирования рынка сельскохозяйственных земель в локальных зонах, различающихся по качеству и плодородию земли, структуре организационно-правовых форм хозяйствования и по степени локализации. В исследуемых зонах структура собственности аналогична другим регионам России, а соотношение различных форм собственности на сельскохозяйственные земли в регионе соответствует российским показателям.

Проведенное исследование основано на анализе статистических данных и результатах экспертной оценки 277 респондентов, в том числе 62 эксперта-управленца администраций муниципальных образований, 215 руководителей предприятий различных форм собственности и работающих собственников, участников локальных рынков полных и ограниченных прав собственности на сельскохозяйственные земли. Большинство экспертов $(88,5 \%)$, являясь коренными местными жителями, владеют земельной собственностью более 10 лет $(80,9 \%)$, имеют определенный опыт участия в рыночных сделках - трансакциях полных и ограниченных прав земельной собственности. Результаты ранжирования неценовых детерминантов спроса и предложения показывают, что в модели спроса на полные права земельной собственности институциональные детерминанты занимают третье место, а в модели предложения - первое место. На рынке прав хозяйствования в моделях спроса и предложения, по мнению экспертов, неценовые детерминанты имеют одинаковую значимость и определяются первым местом (см. таблицу).

Проведенный многофакторный анализ экспертной оценки управленцев позволяет выделить группы факторов, влияющих на функционирование рынка прав земельной собственности.

В 1-ю факторную группу «Институты регулирования рынком» $(23,931$ \%) объединились следующие переменные: возможность спекулятивных сделок с землей и перевод сельскохозяйственных земель в другие категории; возможность монополизации земли в руках небольшой группы собственников; отсутствие должного уровня поддержки местных органов власти. Эта факторная группа отражает низкий уровень регулирующей роли органов власти и, соответственно, содержащиеся в сознании экспертов опасения возможности по поводу противоправных манипуляций с землями при попустительстве местной власти.

Во 2-й факторной группе «Механизм реализации прав земельной собственности» (22,053 \%) объединились четыре переменные: право хозяйствования и форма собственности (земельная доля), цена аренды и налоговая ставка. Из результатов опроса экспертов очевидно, что эти две формы использования земель сельскохозяйственного назначения вступают в противоречивые отношения. В условиях институциональных ограничений (мораторий на куплю-продажу государственных и муниципальных сельскохозяйственных земель), действующих институциональных регуляторах (налоговая ставка), противоречиво- 


\section{Оценка экспертами значимости неценовых детерминантов спроса и предложения} на дуальном рынке прав земельной собственности

\begin{tabular}{|c|c|c|c|}
\hline Модель рынка полных прав собственности & $\begin{array}{l}\text { Ранг зна- } \\
\text { чимости }\end{array}$ & Модель рынка прав хозяйствования & $\begin{array}{l}\text { Ранг зна- } \\
\text { чимости }\end{array}$ \\
\hline \multicolumn{4}{|c|}{ Неиеновые детерминанты спроса } \\
\hline Доходы покупателей (I) & 1 & Институциональные нормы и правила (Ins) & 1 \\
\hline Величина будущей ренты (r) & 2 & Величина транзакционных издержек (C) & 2 \\
\hline Институциональные нормы и правила (Ins) & 3 & Величина трансформационных издержек $\left(\mathrm{C}_{\mathrm{t}}\right)$ & 3 \\
\hline Величина транзакционных издержек (C) & 4 & Риски оппортунизма $\left(\mathrm{R}_{\mathrm{O}}\right)$ & 4 \\
\hline Налоговая ставка (t) & 5 & $\begin{array}{l}\text { Численность владельцев различных форм } \\
\text { собственности }\left(\mathrm{N}_{\mathrm{O}}\right)\end{array}$ & 5 \\
\hline Численность покупателей (N) & 6 & Численность арендаторов (N) & 6 \\
\hline Фактор ожидания (W) & 7 & Качество земли $\left(\mathrm{Q}_{\mathrm{T}}\right)$ & 7 \\
\hline \multirow{2}{*}{$\begin{array}{l}\text { Прочие факторы, в том числе факторы не- } \\
\text { ожиданности (В) }\end{array}$} & \multirow[t]{2}{*}{8} & Индекс времени (t) & 8 \\
\hline & & $\begin{array}{l}\text { Прочие факторы, в том числе факторы не- } \\
\text { ожиданности, климатические условия (B) }\end{array}$ & 9 \\
\hline \multicolumn{4}{|c|}{ Неиеновые детерминанты предложения } \\
\hline Институциональные нормы и правила (Ins) & 1 & Институциональные нормы и правила (Ins) & 1 \\
\hline Численность собственников-продавцов $\left(\mathrm{N}_{\mathrm{O}}\right)$ & 2 & $\begin{array}{l}\text { Альтернативная стоимость, будущая дискон- } \\
\text { тированная стоимость (FDV) }\end{array}$ & 2 \\
\hline Величина транзакционных издержек (C) & 3 & Величина альтернативных издержек (ОС) & 3 \\
\hline Изменение трансформационных издержек $\left(\mathrm{C}_{\mathrm{t}}\right)$ & 4 & Величина трансформационных издержек $\left(\mathrm{C}_{\mathrm{t}}\right)$ & 4 \\
\hline Налоговая ставка (t) & 5 & Издержки контрактации $\left(\mathrm{C}_{\mathrm{c}}\right)$ & 5 \\
\hline $\begin{array}{l}\text { Фактор ожидания - ожидание снижения или } \\
\text { повышения цены земли }\left(\mathrm{W}_{\Delta}\right)\end{array}$ & 6 & Риски оппортунизма $\left(\mathrm{R}_{\mathrm{o}}\right)$ & 6 \\
\hline \multirow{4}{*}{$\begin{array}{l}\text { Прочие факторы, в том числе фактор неожи- } \\
\text { данности (B) }\end{array}$} & \multirow[t]{4}{*}{7} & Земельный налог $\left(\mathrm{T}_{\mathrm{L}}\right)$ & 7 \\
\hline & & Численность арендодателей (N) & 8 \\
\hline & & Индекс времени (t) & 9 \\
\hline & & $\begin{array}{l}\text { Прочие факторы, в том числе факторы не- } \\
\text { ожиданности, климатические условия (B) }\end{array}$ & 10 \\
\hline
\end{tabular}

Примечание. Составлено авторами по результатам мониторинга функционирования локальных рынков Волгоградской области 2018-2019 годов.

го механизма реализации прав на земельную долю преобладает арендная форма землепользования, соответственно развивается рынок прав хозяйствования. Однако большинство экспертов отдают предпочтение полным правам собственности на сельскохозяйственные земли.

В 3-й факторной группе «Ценовая политика и проблемы выбора» (11,378 \%) объединились такие переменные, как высокие цены на землю сельскохозяйственного назначения; отсутствие или недостаток юридической и экономической информации у рядовых участников земельного рынка; возможность получения залога земельного участка; необходимость неформальных отношений при сделках купли-продажи земли. Интерпретация подобного объединения объясняется как необходимость поиска неформальных решений при сделках купли-продажи для рядового участника рынка прав земельной собственности при неблагоприятной ценовой политике. Фактичес- ки это попытки найти симметричный ответ действиям 1-й факторной группы.

В 4-й факторной группе «Соотношение трансформационных и трансакционных издержек» (10,378 \%) объединились переменные: высокие затраты в системе земельного оборота; низкие цены на сельскохозяйственную продукцию; приоритетное право покупки земельных участков местными органами власти; высокая стоимость составления проектов межевания земель. Анализ этой группы факторов показывает доминирование трансакционных издержек над трансформационными издержками. Низкие цены на сопряженных рынках способствуют снижению прибыли и дальнейшей мотивации участия в сельскохозяйственном производстве.

Таким образом, результаты экспертной оценки подтверждают авторскую позицию о доминировании институциональных факторов в структуре спроса и предложения на рынке прав земельной собственности. 


\section{Заключение}

Проведенные исследования рынка прав земельной собственности в аспекте институциональной теории позволяют сделать некоторые выводы относительно сущности, структуры и модели рынка:

- сущность рынка прав земельной собственности определяется как единая система социально-экономических санкционируемых правил поведения агентов рынка по поводу трансакции, спецификации и реализации полных или ограниченных прав земельной собственности в краткосрочном и долгосрочном временных периодах. Участники рынка получают право альтернативного выбора использования редкого ресурса и способов организации хозяйственной деятельности;

- механизм функционирования рынка прав земельной собственности является дуальным с доминированием элементов институционального механизма над рыночным, что обусловлено социальной значимостью земельного ресурса, действующим режимом права земельной собственности и высокими трансакционными издержками функционирования рынка;

- модели спроса и предложения полных и ограниченных прав на земельную собственность отличаются от традиционно представленных в научной литературе моделей тем, что структура неценовых детерминантов отражает взаимосвязь между рыночными и институциональными факторами. В качестве институциональных неценовых детерминантов предлагаются институциональные регуляторы, трансакционные издержки, риски оппортунизма и контрактации, которые обусловливают направления структурных изменений в спросе и предложении;

- результаты эмпирических исследований подтвердили гипотезу о доминировании институциональных факторов в авторских моделях спроса и предложения полных и ограниченных прав земельной собственности, что обусловливает необходимость разработки стратегии институционализации российского рынка прав земельной собственности.

\section{ПРИМЕЧАНИЕ}

\begin{abstract}
${ }^{1}$ Исследование выполнено при финансовой поддержке Российского фонда фундаментальных исследований и Администрации Волгоградской области в рамках научного проекта № 18-410-342001, p_мк «Мониторинг функционирования локальных рынков сельскохозяйственных земель».

The study was funded by RFBR and the Volgograd Region Administration in the framework of research project no. 18-410-342001, p_Mк"Monitoring the Functioning of Local Agricultural Land Markets".
\end{abstract}

\section{СПИСОК ЛИТЕРАТУРЫ}

Алчиан, А. А. Права собственности / А. А. Алчиан // Экономическая теория : пер. с англ. / под ред. Дж. Итуэлла, М. Милгейта, П. Ньюмена ; науч. ред. В. С. Автономов. - М. : ИНФРА-М, 2004. - C. 714-723.

Аношина, Ю. Ф. Экономическая реализация земельной собственности в аграрном секторе : монография / Ю. Ф. Аношина. - Орел : ГТУ, 2011. $-360 \mathrm{c}$.

Веретенникова, А. Ю. Концепция институционального механизма в экономической теории / А. Ю. Веретенникова, Ж. К. Омонов // Журнал экономической теории. - 2017. № 2. - C. 156-162.

Гущина, Е. Г. Сущность маркетингового механизма взаимодействия субьектов социально-значимых рынков - рынков образовательных услуг и рынков труда / Е. Г. Гущина, В. В. Шиховец // Современная экономика: проблемы и решения. -2010 . - № 3. - С. 90-100.

Иншаков, О. В. «Ядро развития» в контексте новой теории факторов производства / О. В. Иншаков // Экономическая наука современной России. - 2003. - № 1. - С. 11-25.

Капелюшников, Р. И. Экономическая теория прав собственности (методология, основные понятия, круг проблем) / Р. И. Капелюшников ; под. ред. В. Н. Кузнецова. - М. : ИЭ АНСССР, 1990. - 90 с.

Кресникова, Н. И. Механизмы функционирования земельного рынка / Н. И. Кресникова // Земельный вестник. - 2003. - № 3. - С. 10-15.

Макаров, А. Н. Реализация земельной собственности: системный и институционально-эволюционный подходы : монография / А. Н. Макаров. Казань : Изд-во Казан. гос. ун-та, 2007. - 439 с.

Норт, Д. Институциональные изменения: рамки анализа / Д. Норт // Вопросы экономики. 1997. - № 3. - С. 6-17.

Оганесян, Л. О. Дуальный подход к исследованию механизма функционирования рынка земли 
/ Л. О. Оганесян, Е. Н. Федюнина // Вестник Волгоградского государственного университета. Серия 3, Экономика. Экология. - 2015. № 3 (32). - C. 27-37. - DOI: http://dx.doi.org/ 10.15688/jvolsu3.2015.3.3.

Оганесян, Л. О. Концептуальные подходы к исследованию функционирования рынка сельскохозяйственных земель / Л. О. Оганесян, Е. Н. Федюнина // Известия Волгоградского государственного технического университета. Серия: Актуальные проблемы реформирования российской экономики (теория, практика, перспективы) : межвуз. сб. науч. ст. - Волгоград : ВолгГТУ, 2014. - Вып. 20, № 17 (144). -С. 100-106.

Оганесян, Л. О. Теоретические подходы к формированию модели рынка прав собственности на сельскохозяйственные земли / Л. О. Оганесян, Е. Н. Федюнина, А. В. Воробьев // Бизнес. Образование. Право. - 2019. - № 3 (48). C. 156-161.-DOI: 10.25683/VOLBI.2019.48.353.

Поланьи, К. Великая трансформация: политические и экономические истоки нашего времени / К. Поланьи ; пер. с англ. А. А. Васильева, С. Е. Федорова, А. П. Шурбелева; под общ. ред. С. Е. Федорова. - СПб. : Алетейя, 2002. - 320 с.

Попов, Е. В. Институциональные факторы экономических изменений теории Дугласа Норта / Е. В. Попов, О. С. Сухарев // Журнал экономической теории. - 2016. - № 3. - С. 117-133.

Тамбовцев, В. Л. Институциональный рынок как механизм институциональных изменений / В. Л. Тамбовцев // Общественные науки и современность. - 2001. - № 5. - С. 25-28.

Федюнина, Е. Н. Парадигма земельной собственности в контексте теории прав собственности / Е. Н. Федюнина, Л. О. Оганесян, А. В. Воробьев // Финансовая экономика. - 2018. - № 9, ч. 4. - С. 400- 404.

Alchian,A.A. The property rights paradigm/A.A.Alchian, H. Demsetz // The Journal of Economic History. 1973. - Vol. 33. - P. 16-27.

Furubotn, E. G. Property Rights and Economic Theory: A Survey of Recent Literature/ E. G. Furubotn, S. Pejovich // Journal of Economic Literature. 1972. - Vol. 10, iss. 4. - P. 1137-1162.

Gushchina, E. G. Mechanisms of Interaction of the Socially Significant Markets: Monograph / Gushchina E. G. - Saarbrucken (Germany) : LAP LAMBERT Academic Publishing GmbH \& Co. KG, 2012. $-358 \mathrm{p}$.

Honore, A. M. Ownership / A. M. Honore ; ed. by A. G. Guest // Oxford Essays in Jurisprudence. L. : Oxford University Press, 1961. - 292 p.

Peiovich, S. The Market for Institution Versus Capitalism by Fiat / S. Peiovich // Kyklos. - 1994. - Vol. 47.P. 519-528.
Pejovich, S. The Market for Institutions Versus the Strong Hand of the State: the Case of Eastern Europe / S. Pejovich ; B. Dallago and L. Mittone (eds.) // Economic Institutions, Markets and Competition.-Cheltenham : EdwardElgar, 1996.P. 111-126.

Polany, K. The Self-Regulating Market and the Fictitious Commodities: Labor, Land and Money / K. Polany // The Great Transformation. - N. Y. : Farrar \& Rinehart, Inc., 1944. - P. 68-76.

\section{REFERENCES}

Alchian A.A. Prava sobstvennosti [Property Rights]. Itwell J., Milgate M., Newman P., eds. Ekonomicheskaya teoriya [Economic Theory]. Moscow, INFRA-M Publ., 2004, pp. 714-723.

Anoshina Yu.F. Ekonomicheskaya realizatsiya zemelnoy sobstvennosti $v$ agrarnom sektore: monografiya [Economic Implementation of Land Property in the Agricultural Sector. Monograph]. Orel, GTU, 2011.360p.

Veretennikova A.Yu., Omonov Zh.K. Kontseptsiya institutsionalnogo mekhanizma $\mathrm{V}$ ekonomicheskoy teorii [The Concept of the Institutional Mechanism in Economic Theory]. Zhurnal ekonomicheskoy teorii [Russian Journal of Economic Theory], 2017, no. 2, pp. 156-162.

Gushchina E.G., Shikhovets V.V. Sushchnost marketingovogo mekhanizma vzaimodeystviya subyektov sotsialno-znachimykh rynkov rynkov obrazovatelnykh uslug i rynkov truda [The Essence of the Marketing Mechanism for the Interaction of Subjects of Socially Significant Markets - Educational Services Markets and Labor Markets]. Sovremennaya ekonomika: problemy $i$ resheniya [Modern Economics: Problems and Solutions], 2010, no. 3, pp. 90-100.

Inshakov O.V. «Yadro razvitiya» v kontekste novoy teorii faktorov proizvodstva ["The Core of Development" in the Context of a New Theory of Production Factors]. Ekonomicheskaya nauka sovremennoy Rossii [Economics of Contemporary Russia], 2003, no. 1, pp. 11-25.

Kapelyushnikov R.I. Ekonomicheskaya teoriya prav sobstvennosti (metodologiya, osnovnye ponyatiya, krug problem) [Economic Theory of Property Rights (Methodology, Basic Concepts, Range of Problems)]. Moscow, IE AN SSSR, 1990. 90 p.

Kresnikova N.I. Mekhanizmy funktsionirovaniya zemelnogo rynka [Mechanisms for the Functioning of the Land Market]. Zemelnyy vestnik, 2003, no. 3, pp. 10-15. 
Makarov A.N. Realizatsiya zemelnoy sobstvennosti: sistemnyy $i$ institutsionalno-evolyutsionnyy podkhody: monografiya [Implementation of Land Property: Systemic and InstitutionalEvolutionary Approaches. Monograph]. Kazan, Izd-vo Kazanskogo gosudarstvennogo universiteta, 2007. $439 \mathrm{p}$.

Nort D. Institutsionalnye izmeneniya: ramki analiza [Institutional Change: A Framework for Analysis]. Voprosy ekonomiki, 1997, no. 3, pp. 6-17.

Oganesyan L.O., Fedyunina E.N. Dualnyy podkhod k issledovaniyu mekhanizma funktsionirovaniya rynka zemli [Dual Approach to the Study of the Mechanism of Functioning of the Land Market]. Vestnik Volgogradskogo gosudarstvennogo universiteta. Seriya 3. Ekonomika. Ekologiya [Science Journal of Volgograd State University. Global Economic System], 2015, no. 3 (32), pp. 27 37. DOI: http://dx.doi.org/10.15688/jvolsu3. 2015.3.3.

Oganesian L.O., Fedyunina E.N. Kontseptualnye podkhody $\mathrm{k}$ issledovaniyu funktsionirovaniya rynka selskokhozyaystvennykh zemel [Conceptual Approaches to the Study of the Functioning of Agricultural Land Market]. Izvestiya Volgogradskogo gosudarstvennogo tekhnicheskogo universiteta. Seriya: Aktualnye problemy reformirovaniya rossiyskoy ekonomiki (teoriya, praktika, perspektivy): mezhvuz. sb. nauch. st. [Bulletin of Volgograd State Technical University: Series "Current Problems of Reforming Russian Economy (Theory, Practice, Prospects)". Interuniversity Collection of Scientific Articles]. Volgograd, VolgGTU, 2014, iss. 20, no. 17 (144), pp. 100-106.

Oganesyan L.O., Fedyunina E.N., Vorobyev A.V. Teoreticheskie podkhody $\mathrm{k}$ formirovaniyu modeli rynka prav sobstvennosti na selskokhozyaystvennye zemli [Theoretical Approaches to Development of a Model of the Market of Property Rights on Agricultural Lands]. Biznes. Obrazovanie. Pravo [Business. Education. Law], 2019, no. 3 (48), pp. 156-161. DOI: 10.25683/VOLBI.2019.48.353.

Polanyi K. Velikaya transformatsiya: politicheskie $i$ ekonomicheskie istoki nashego vremeni [The
Great Transformation: Political and Economic Origins of Our Time]. Saint Petersburg, Aleteya Publ., 2002.320 p.

Popov E.V., Sukharev O.S. Institutsionalnye faktory ekonomicheskikh izmeneniy teorii Duglasa Norta [Institutional Factors of Economic Change in Douglas North Theory]. Zhurnal ekonomicheskoy teorii [Russian Journal of Economic Theory], 2016, no. 3, pp. 117-133.

Tambovtsev V.L. Institutsionalnyy rynok kak mekhanizm institutsionalnykh izmeneniy [Institutional Market as a Mechanism of Institutional Change]. Obshchestvennye nauki $i$ sovremennost [Social Sciences and Contemporary World], 2001, no. 5, pp. 25-28.

Fedyunina E.N., Oganesyan L.O., Vorobyev A.V. Paradigma zemelnoy sobstvennosti v kontekste teorii prav sobstvennosti [The Paradigm of Land Ownership in the Context of the Theory of Property Rights]. Finansovaya ekonomika [Financial Economy], 2018, no. 9, part 4, pp. 400-404.

Alchian A.A., Demsetz H. The Property Rights Paradigm. The Journal of Economic History, 1973, vol. 33, pp. 16-27.

Furubotn E.G., Pejovich S. Property Rights and Economic Theory: A Survey of Recent Literature. Journal of Economic Literature, 1972, vol. 10, iss. 4, pp. 1137-1162.

Gushchina E.G. Mechanisms of Interaction of the Socially Significant Markets. Monograph. Saarbrucken, LAP LAMBERT Academic Publishing GmbH \& Co. KG, 2012. 358 p.

Honore A.M. Ownership. Oxford Essays in Jurisprudence. London, Oxford University Press, 1961. 292 p.

Peiovich S. The Market for Institution Versus Capitalism by Fiat. Kyklos, 1994, vol. 47, pp. 519-528.

Pejovich S. The Market for Institutions Versus the Strong Hand of the State: The Case of Eastern Europe. Dallago B., Mittone L., eds. Economic Institutions, Markets and Competition. Cheltenham, Edward Elgar, 1996, pp. 111-126.

Polany K. The Self-Regulating Market and the Fictitious Commodities: Labor, Land and Money. Polany K. The Great Transformation. New York, Farrar \& Rinehart, Inc., 1944, pp. 68-76. 


\section{ЭКОНОМИЧЕСКАЯ ТЕОРИЯ}

\section{Information About the Authors}

Elena N. Fedyunina, Candidate of Sciences (Economics), Associate Professor, Department of Social and Cultural Service, Volgograd State Agrarian University, Prosp. Universitetsky, 26, 400002 Volgograd, Russian Federation, elena.fedyunina@mail.ru, https://orcid.org/0000-0002-5243-6397

Liliya O. Oganesyan, Candidate of Sciences (Economics), Associate Professor, Department of Land Management and Cadastres, Volgograd State Agrarian University, Prosp. Universitetsky, 26, 400002 Volgograd, Russian Federation, oganesian@bk.ru, https://orcid.org/0000-0002-9170-5588

\section{Информация об авторах}

Елена Николаевна Федюнина, кандидат экономических наук, доцент кафедры социально-культурного сервиса, Волгоградский государственный аграрный университет, просп. Университетский, 26, 400002 г. Волгоград, Российская Федерация, elena.fedyunina@mail.ru, https://orcid.org/0000-0002-5243-6397

Лилия Оганесовна Оганесян, кандидат экономических наук, доцент кафедры землеустройства и кадастров, Волгоградский государственный аграрный университет, просп. Университетский, 26, 400002 г. Волгоград, Российская Федерация, oganesian@bk.ru, https://orcid.org/0000-0002-9170-5588 